
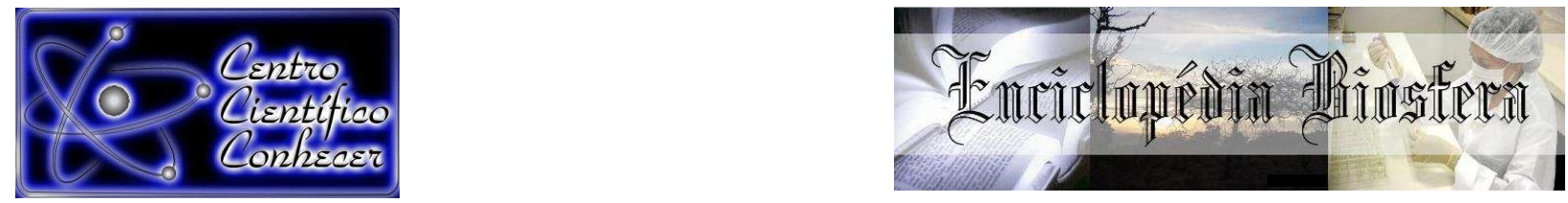

\title{
RESISTÊNCIA DO SOLO À PENETRAÇÃO EM ÁREAS SOB O SISTEMA DE INTEGRAÇÃO LAVOURA-PECUÁRIA-FLORESTA, NA REGIÃO AMAZÔNICA
}

Benhur da Silva Oliveira ${ }^{1}$, Marco Antonio Camillo de Carvalho ${ }^{2}$, Anderson Lange $^{3}$, Rivanildo Dallacort ${ }^{2}$, Valvenarg Pereira da Silva ${ }^{4}$

1 Engenheiro Florestal, Mestre em Ambiente e Sistemas de Produção Agrícola, professor do Departamento de Agronomia - Universidade do Estado de Mato Grosso

- Tangará da Serra-Mato Grosso, Brasil - (benhur.florestal@hotmail.com)

2 Professor Doutor do Programa de Mestrado em Ambiente e Sistemas de Produção

Agrícola da Universidade do Estado de Mato Grosso-Tangará da Serra -Mato Grosso, Brasil

3 Professor Doutor em Ciências (Energia Nuclear na Agricultura) - Departamento de Agronomia da Universidade Federal do Mato Grosso - Sinop-Mato Grosso, Brasil 4 Biólogo - Doutorando em Biodiversidade e Biotecnologia da Amazônia Legal, Rede BIONORTE, Universidade do Estado de Mato Grosso, Cáceres, Mato Grosso, Brasil

Recebido em: 08/09/2015 - Aprovado em: 14/11/2015 - Publicado em: 01/12/2015 DOI: http://dx.doi.org/10.18677/Enciclopedia_Biosfera_2015_255

\section{RESUMO}

A presente pesquisa teve como objetivo avaliar a resistência do solo à penetração (RSP) em um sistema de integração lavoura-pecuária-floresta. O desenvolvimento da pesquisa ocorreu em uma Unidade de Referência Tecnológica de integração lavoura-pecuária-floresta implantada em 20 hectares da Fazenda Gamada, no município de Nova Canaã do Norte, Mato Grosso. O delineamento utilizado foi o inteiramente casualizado em arranjo fatorial $(6 \times 2 \times 8)$, sendo seis tratamentos (usos): Pinho Cuiabano, Pau-balsa, Teca, Eucalipto, solos sob vegetação nativa e pastagem no sistema convencional, dois locais de avaliações, entre os renques florestais e na faixa de pastagem, e oito profundidades (em secções de 0,05 $\mathrm{m}$ até a profundidade de 0,40 m do solo), com três repetições. Os maiores valores de RSP foram observados nos tratamentos: Eucalipto, Teca e Pastagem convencional, apresentando respectivamente 7,97; 5,63 e 5,12 MPa, sendo estes os tratamentos que apresentaram os menores percentuais de umidade do solo, acrescidos pelo tratamento Pau-balsa com 19,85\% de umidade, o qual apresentou menor taxa de umidade entre os tratamentos. Acrescenta-se que a baixa umidade do solo e a pressão exercida pelo pisoteio dos animais e impedimento físico (raízes), foram condicionantes para os elevados valores de RSP.

PALAVRAS-CHAVE: Agrossilvipastoril;Floresta; iLPF; Sistemas integrados; 


\title{
SOIL PENETRATION RESISTANCE IN AREAS UNDER INTEGRATED CROP- LIVESTOCK-FOREST SYSTEM IN THE AMAZON REGION
}

\begin{abstract}
This research aimed to evaluate the soil penetration resistance (RSP) in an area under an integrated crop-livestock-forest system. The study was conducted in a Technology Reference Unit (RUT) with integrated crop-livestock-forest System (ILPF) implanted in 20 hectares of Gamada Farm in the city of Nova Canaã do Norte, Mato Grosso. The experimental design was in completely randomized factorial $(6 \times 2 \times 8)$, six treatments (uses): Pinho-cuiabano, Pau-balsa, Teca and Eucalipto, two local ratings, between forest rows and pasture in conventional system, and eight soil depth (in 0.05 $\mathrm{m}$ sections, to a depth of $0.40 \mathrm{~m}$ ), with three replications. The highest RSP values were observed in the treatments Teca, Eucalipto and Pasture, with, respectively, 7.97, 5.63 and $5.12 \mathrm{MPa}$, which are the treatments that had the lowest percentages of soil moisture, plus the treatment Pau-balsa with $19.85 \%$ moisture, which showed the lowest moisture between the treatments. The low soil moisture, the pressure exerted by live-stock trampling and physical obstacles (roots), were conditions for high values of RSP.
\end{abstract}

KEYWORDS: Agrossilvipastoril; iLPF; Integrated systems; Forest

\section{INTRODUÇÃO}

A adoção de sistemas de integração Lavoura-Pecuária-Florestas (iLPF), temse apresentado como uma alternativa para a sustentabilidade do solo de uso agrícola. Este sistema tem obtido destaque como potencial estratégico na produção agropecuária sustentável nos trópicos (FRANCHINI et al., 2011), tornando-se importante ferramenta do programa do Ministério da Agricultura Pecuária e Abastecimento para o Plano da Agricultura de Baixo Carbono (Plano ABC).

No entanto, devido as interações entre as culturas agrícolas, florestais e a pecuária tal sistema torna-se complexo, e como enfatiza BALBINO et al. (2011), é necessário pesquisas científicas e tecnológicas para que se alcance uma consolidação quanto à sua sustentabilidade ambiental e produtiva. Os mesmo destacam ainda, a importância das pesquisas serem regionalizadas e contínuas, em especial referentes aos atributos físicos, químicos e biológicos do solo.

Segundo STEFANOSKI et al. (2013), conhecer os atributos físicos, químicos e biológicos do solo são fundamentais e servem como indicadores da qualidade do solo e do ambiente, e que estes devem ser foco de trabalhos constantes na avaliação de sistemas produtivos, com o objetivo de se adaptar sistemas ou propor usos mais sustentáveis do solo.

Os solos agrícolas funcionam como um sistema complexo, sendo condicionado através de sua qualidade física a função de sustentação das plantas, bem como o suprimento de nutrientes, água e oxigênio para as mesmas (COSTA et al., 2012). As condições físicas do solo alteram diretamente e indiretamente a produção vegetal e a qualidade ambiental do solo (SILVEIRA et al., 2010).

Dentre os principais indicadores físicos de qualidade do solo sob o ponto de vista agrícola, destacam-se, à textura, estrutura, resistência à penetração, profundidade de enraizamento, capacidade de água disponível, percolação ou transmissão da água e o sistema de cultivo (EMBRAPA, 2006).

Vários autores utilizam e denominam a resistência do solo à penetração como propriedade adequada para expressar a facilidade de penetração das raízes no solo e o grau de compactação do mesmo (RIBON et al., 2003; SILVEIRA et al., 2010). 
Vale ressaltar que a resistência do solo à penetração apresenta relação direta com a umidade do solo, teor de matéria orgânica, textura e a densidade do solo.

Considerando-se o efeito dos diferentes tipos de uso e manejo sobre as propriedades do solo, este trabalho teve como objetivo avaliar a resistência do solo à penetração em um sistema de integração Lavoura-Pecuária-Floresta, implantadas com quatros espécies florestais e em uma área com vegetação nativa e pastagem conduzida pelo sistema convencional.

\section{MATERIAL E MÉTODOS}

Área de estudo - A presente pesquisa foi desenvolvida em uma Unidade de Referência Tecnológica (URT) de integração lavoura-pecuária-floresta (iLPF) implantada em 20 hectares na Fazenda Gamada, coordenadas 1024'10" S, 5543' 22" W, no município de Nova Canaã do Norte-MT.

Segundo a classificação de Köppen, a região apresenta clima tipo Awi (Tropical chuvoso) com nítida estação de seca. A temperatura média anual varia entre $20^{\circ} \mathrm{C}$ e $38^{\circ} \mathrm{C}$, com média de $26^{\circ} \mathrm{C}$ (FERREIRA, 2001). A média anual de precipitação pluviométrica da área nos últimos seis anos foi de $2.175 \mathrm{~mm}$. O solo da área experimental é classificado como Latossolo Vermelho Amarelo Distroférrico de textura média. Dois meses antes da instalação do experimento, o solo foi amostrado na profundidade de $0-20 \mathrm{~cm}$, apresentando as seguintes características químicas: $\mathrm{pH}_{\mathrm{H} 2 \mathrm{O}}=5,70 ; \mathrm{P}$ (Mehlich) $=2,50 \mathrm{mg} \mathrm{dm}^{-3} ; \mathrm{K}($ Mehlich $)=111 \mathrm{mg} \mathrm{dm}^{-3} ; \mathrm{Ca}=1,56 \mathrm{cmolc}$ $\mathrm{dm}^{-3} ; \mathrm{Mg}=0,44 \mathrm{cmolc} \mathrm{dm}^{-3} ; \mathrm{Al}=0,00 \mathrm{cmolc} \mathrm{dm}^{-3} ; \mathrm{MO}=17,00 \mathrm{~g} \mathrm{dm}^{-3}$.

A área de 20 hectares foi subdividida por quatros tratamentos de cinco hectares cada, os quais foram caracterizados e diferenciados de acordo com a espécie florestal implantada. Utilizou-se uma área adjacente a área de iLPF, as quais possuem a mesma classe de solo e topografia com vegetação nativa e pastagem conduzida pelo sistema convencional.

Em 1998 a área da URT - iLPF teve sua vegetação original de Floresta Ombrófila desmatada para a implantação de pastagem com braquiarão (Brachiaria brizantha cv. Marandu), a qual foi mantida por dois anos. Em seguida a área foi utilizada para o cultivo de culturas anuais durante seis anos consecutivos, sendo: dois anos com arroz e quatro anos com soja e uma segunda safra com milho. Depois desse período a lavoura foi substituída pela pastagem novamente com braquiarão, a qual permaneceu na área por outros dois anos (2006-2008), até a implantação do experimento aqui avaliado.

$\mathrm{Na}$ implantação do experimento a pastagem foi dessecada e efeituou-se o preparo somente das faixas de plantio das árvores (cultivo mínimo). Em janeiro de 2009, nos sulcos centrais foi realizado o plantio de mudas das espécies florestais Pinho Cuiabano (Schizolobium amazonicum), Pau-balsa (Ochroma pyramidale), Teca (Tectona grandis) e Eucalipto (Eucalyptus urograndis) em linha tripla, intercalada por faixas de 20 metros de largura destinadas à implantação das atividades agrícola e pecuária (Tabela 1).

No primeiro ano de estudo, juntamente com o plantio das espécies florestais, foi cultivado arroz, variedade BRS Monarca, com densidade de semeio de $70 \mathrm{~kg}$ de sementes por ha ${ }^{-1}$, no espaçamento de 0,42 m entre linhas. Na semeadura foram aplicados $400 \mathrm{~kg} \cdot \mathrm{ha}^{-1}$ do formulado de NPK 01-18-18 + micronutrientes. Nove dias após emergência foram aplicados $70 \mathrm{~kg} \cdot \mathrm{ha}^{-1}$ de uréia (45\% de N), e uma semana depois aplicou-se outra dose de $40 \mathrm{~kg} \mathrm{ha}^{-1}$ de uréia, ambas conduzidas à lanço em 
superfície. Após 115 dias da semeadura, o arroz foi colhido, obtendo produtividade média de $3.600 \mathrm{~kg}$ ha ${ }^{-1}$. Neste ano não houve plantio da segunda safra, sendo conduzida a rebrota da Brachiaria brizantha cv. Marandu.

No segundo ano agrícola (Safra 2009/10) cultivou-se a soja variedade BRS Flora, no espaçamento de 0,40 m entrelinhas, com densidade de 14 sementes $\mathrm{m}^{-1}$. Foram aplicados $318 \mathrm{~kg} \cdot \mathrm{ha}^{-1}$ de superfosfato simples $\left(18 \%\right.$ de $\left.\mathrm{P}_{2} \mathrm{O}_{5}\right)$ como adubação de semeadura e, 32 dias após a emergência das plântulas, foi realizada a adubação de cobertura com $105 \mathrm{~kg} \cdot$ ha $^{-1}$ de cloreto de potássio $\left(58 \%\right.$ de $\left.\mathrm{K}_{2} \mathrm{O}\right)$. A colheita da soja foi realizada 106 dias após a semeadura, obtendo-se produtividade média de $3.546 \mathrm{~kg} \mathrm{ha}^{-1}$. Como plantio de segunda safra, cultivou-se arroz precoce, porém devido à severa seca que atingiu a região norte em 2010, a colheita se tornou inviável.

No terceiro ano agrícola (safra 2010/11), visando à introdução da componente pecuária no sistema, cultivou-se soja precoce (BRS Flora), com o mesmo manejo conduzido na safra 2009/2010. Porém na safra 2010/2011 a produtividade foi menor, alcançando média de $2.900 \mathrm{~kg} \mathrm{ha}^{-1}$. Para a introdução da pecuária, foi implantada e conduzida a pastagem com Brachiaria ruzizienssis. Em análise parcial da produtividade da área experimental, com o manejo sendo rotacionado pela altura da forrageira a taxa de lotação média da área é de 3,7 animais ha ${ }^{-1}$, com ganho de $1,040 \mathrm{~kg} \mathrm{dia}^{-1}$.animal ${ }^{-1}$ (Raça: $\mathrm{F} 1$-cruzamento industrial resultante da Rúbia galega $\mathrm{x}$ Nelore) na fase recria e terminação.

Coleta e análise dos dados - $O$ delineamento experimental utilizado foi 0 inteiramente casualizado em arranjo fatorial $(6 \times 2 \times 8)$, sendo seis usos (sistemas integrados composto por quatro espécies florestais, vegetação nativa e pastagem convencional), dois locais de avaliações (entre os renques florestais e na faixa de pastagem), e oito profundidades (em secções de $0,05 \mathrm{~m}$ até a profundidade de 0,40 $\mathrm{m}$ do solo), com três repetições. Na Tabela 1, encontra-se a relação dos tratamentos, com a caracterização das amostragens e do tratamento. As amostragens do local de avaliação floresta foram realizadas na linha central dos renques triplo dos indivíduos florestais, já no local de avaliação pastagem foram realizadas as amostragens no centro da faixa.

Todas as amostragens foram realizadas de forma aleatória, no tratamento vegetação nativa observou-se um distanciamento da borda, para que a mesma não tivesse interferência nos resultados.

Para determinação da resistência do solo à penetração, utilizou-se o penetrômetro de impacto Modelo Planalsucar-Stolf com ponta cônica de 2,27 cm${ }^{2}$, êmbolo de 1,58 kg, aparelho de $1,53 \mathrm{~kg}$, e altura de queda do embolo de 0,412 m.

TABELA 1, Tratamentos, número de amostragens em cada local de avalição e espaçamento de cada tratamento.

\begin{tabular}{|c|c|c|c|}
\hline \multirow[t]{2}{*}{ Tratamento (uso) } & Floresta & Pastagem & \multirow{2}{*}{$\begin{array}{c}\text { Espaçamento } \\
(\mathrm{m})\end{array}$} \\
\hline & \multicolumn{2}{|c|}{$\mathrm{N}^{\circ}$ de amostragens } & \\
\hline Eucalipto & 9 & 9 & $20 \times 3 \times 2$ \\
\hline Teca & 9 & 9 & $20 \times 3 \times 2$ \\
\hline Pinho cuiabano & 9 & 9 & $20 \times 3 \times 3$ \\
\hline Pau-balsa & 9 & 9 & $20 \times 3 \times 3$ \\
\hline Vegetação nativa & 9 & ** & -- \\
\hline Pastagem convencional & ** & 9 & -- \\
\hline
\end{tabular}

** Não apresentam locais diferentes para avaliação 
Para a realização dos cálculos da resistência mecânica dos solos à penetração utilizou-se as considerações de SÁ \& JUNIOR (2007). A transformação da penetração da haste do aparelho (cm.impacto) em resistência à penetração foi obtida através da expressão dos "holandeses" (Eq. 1) determinada pelo índice de cone (IC):

$$
\mathrm{IC}=\left(\frac{\mathrm{Mg}+\mathrm{mg}}{\mathrm{A}}\right)+\left[\left(\frac{\mathrm{M}}{\mathrm{M}+\mathrm{m}}\right) *\left(\frac{\mathrm{Mg} * \mathrm{~h}}{\mathrm{~A} * \mathrm{P}}\right)\right]
$$

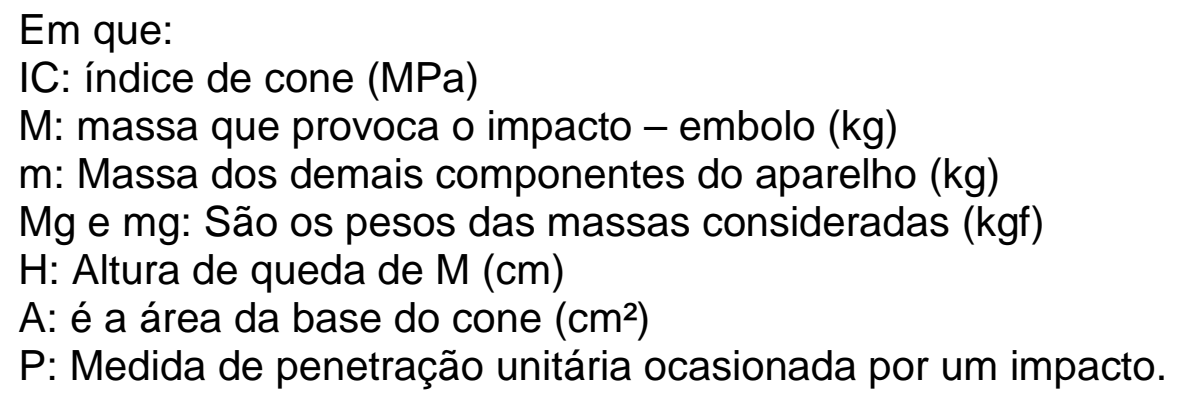

As amostragens foram realizadas em junho de 2012. Para determinação da umidade do solo no momento da amostragem, foram coletadas três amostras de solo de cada tratamento (uso). Ressalta-se que a umidade do solo foi realizada apenas para a camada de 0-0,10 $\mathrm{m}$ de profundidade, no intuito de avaliar as condições de cada ponto de avaliação. Após a coleta do solo o mesmo foi condicionado em sacos plásticos e, posteriormente levados para análise conforme Embrapa (1997) no Laboratório de Solos e Análise Foliar da Universidade do Estado de Mato Groso - UNEMAT, Campus de Alta Floresta.

Os dados foram submetidos à análise de variância e quando significativo às médias foram comparadas pelo teste de Tukey a $5 \%$, com auxílio do programa estatístico Sisvar (FERREIRA, 2011).

\section{RESULTADO E DISCUSSÃO}

A resistência do solo à penetração (RSP) diferiu estatisticamente nas diferentes profundidades, usos e locais, conforme apresentando na Tabela 2. Foi verificada interação dupla entre os fatores Profundidade/Uso e Uso/local.

$\mathrm{Na}$ Tabela 3 são descritos os valores médios de resistência do solo à penetração e umidade do solo da camada superficial em função dos diferentes usos, locais e profundidades, observa-se que a maior umidade do solo foi verificada na vegetação nativa, a qual foi superior aos demais usos. Essa maior umidade na vegetação nativa relaciona-se com o maior sombreamento e acúmulo de serapilheira ocorrido neste uso. Pesquisas realizas por IORI et al., (2012) obtiveram resultados semelhantes quando comparado diversos usos da terra (cultivo de banana, pastagem degrada, sistema silvipastoril e mata nativa), em que a mata nativa se sobressaiu no quesito umidade dos demais usos, tais autores também elencam que o nível de sombreamento influencia diretamente na umidade do solo. 
TABELA 2. Valores de $\mathrm{F}$ e coeficiente de variação $(\mathrm{CV} \%)$ da Resistência do Solo à Penetração (RSP) e umidade do solo em função de diferentes usos e locais, em um experimento em Nova Canaã do Norte - MT, (2012).

\begin{tabular}{ccc}
\hline Fonte de variação & RSP & Umidade do solo \\
\hline Profundidade & $3,80^{\star *}$ & -- \\
Uso & $66,14^{\star *}$ & $108,12^{\star *}$ \\
Local & $63,48^{\star \star}$ & $238,50^{\star \star}$ \\
Profundidade x uso & $6,07^{\star *}$ & -- \\
Profundidade x local & $0,279^{\text {ns }}$ & -- \\
Uso x Local & $21,23^{\star *}$ & -- \\
Profundidade x Uso x Local & $2,38^{\text {ns }}$ & -- \\
\hline CV (\%) & 32,80 & 3,19 \\
\hline
\end{tabular}

**- Significativo ao nível de $1 \%$ de probabilidade

*- Significativo ao nível de $5 \%$ de probabilidade

ns - Não significativo

Com relação à RSP nos locais de amostragens, o melhor comportamento foi verificado na pastagem convencional, tal resultado é atribuído pelos benefícios da integração Lavoura-Pecuária-Floresta, conforme já abordado por CHIODEROLI et al. (2012), que devido a prática de integração ocorre a melhora das condições físicas do solo devido à maior produção de palha, favorecendo a infiltração de água, permitindo maior exploração do perfil do solo pelas raízes, e consequentemente a manutenção da estabilidade do sistema.

No local vegetação nativa o aumento da RSP pode ser atribuído ao pisoteio e permanência do gado, uma vez que neste local apresenta sombreamento ocasionado pelas copas das árvores que auxilia no conforto térmico dos animais. A compressão do solo acarretado pelo crescimento das raízes, também pode ter contribuído para o aumento da RSP. Segundo YOUNG (1998) em estudos do comportamento de raízes com o solo atribuem o impacto negativo (compactação) do solo ao desenvolvimento radicular de plantas.

Nas três primeiras profundidades $(0,00-0,15 \mathrm{~m})$ a maior resistência foi verificada no uso Eucalipto apresentando valor superior aos demais usos (Tabela 4). Essa maior resistência à penetração deve-se ao maior número de raízes presentes neste uso. Ainda nestas primeiras camadas a menor resistência foi verificada para a Vegetação nativa, que não diferiu dos usos Pau-balsa e Pinho cuiabano (Tabela 4), destacando-se estes usos como melhoradores da qualidade física do solo.

Essa menor resistência observada nos usos Pau-balsa e Vegetação nativa pode ser atribuída ao acúmulo de matéria orgânica na camada superficial do solo, tais resultados corroboram com as pesquisas de CARVALHO et al., (2004) em que os mesmos avaliando os atributos físicos do solo em sistema agroflorestal atribui a baixa RSP na profundidade $0,00-0,10 \mathrm{~m}$ à incorporação de matéria orgânica ocasionada por esses sistemas. 
TABELA 3. Valores médios de resistência do solo à penetração em função de diferentes usos e locais de amostragem. Nova Canaã do Norte - MT, 2012

\begin{tabular}{|c|c|c|}
\hline & RSP (Mpa) & Umidade do solo (\%) \\
\hline \multicolumn{3}{|l|}{ Uso (U) } \\
\hline Vegetação Nativa & 2,88 & $28,80 \mathrm{a}$ \\
\hline Pastagem convencional & 5,12 & $20,79 d$ \\
\hline Eucalipto & 7,97 & $22,93 \mathrm{c}$ \\
\hline Pau-balsa & 3.14 & $19.85 d$ \\
\hline Teca & 5,63 & $23,06 \mathrm{bc}$ \\
\hline Pinho cuiabano & 3,81 & $24,33 \mathrm{~b}$ \\
\hline DMS (Tukey $5 \%$ ) & 0,91 & 1,32 \\
\hline \multicolumn{3}{|l|}{ Local (L) } \\
\hline Floresta & 5,43 & $21,38 b$ \\
\hline Pastagem & 3,98 & $25,20 \mathrm{a}$ \\
\hline DMS (Tukey 5\%) & 0,36 & 0,51 \\
\hline \multicolumn{3}{|l|}{ Profundidade (P) } \\
\hline $0,00-0,05$ & 4,26 & -- \\
\hline $0,05-0,10$ & 5,27 & -- \\
\hline $0,10-0,15$ & 5,27 & -- \\
\hline $0,15-0,20$ & 5,29 & -- \\
\hline $0,20-0,25$ & 4,72 & -- \\
\hline $0,25-0,30$ & 4,47 & -- \\
\hline $0,30-0,35$ & 4,15 & -- \\
\hline $0,35-0,40$ & 4,23 & -- \\
\hline
\end{tabular}

DMS: Diferença mínima significativa.

Médias seguidas pela mesma letra não diferem estatisticamente entre si ao nível de $5 \%$ de probabilidade pelo teste de Tukey.

$\mathrm{Na}$ quarta e quinta profundidade $(0,15-0,25 \mathrm{~m})$ a maior resistência ainda é observada no uso Eucalipto, no entanto esta não difere dos usos Teca e Pastagem convencional. Nas três últimas profundidades 0,25-0,30; 030-0,35 e 0,35-0,40 m já não ocorre diferença entre os usos, mostrando assim que a partir da profundidade de $0,25 \mathrm{~m}$ não se observa interferência antrópica sobre a RSP. Dados similares foram obtidos por DEBIASE \& FRANCHINI (2012) na avaliação da RSP em área de integração lavoura-pecuária com diferentes intensidades de pastejo, onde observaram nível de compactação do solo pelos diferentes tipos de usos até a camada de $0,30 \mathrm{~m}$ do solo.

TABELA 4 - Resistência mecânica a penetração em função de usos dentro de cada profundidade. Nova Canaã do Norte-MT, 2012

\begin{tabular}{ccccccc}
\hline \multirow{2}{*}{$\begin{array}{c}\text { Profundidades } \\
(\mathrm{m})\end{array}$} & $\begin{array}{c}\text { Pinho } \\
\text { Cuiabano }\end{array}$ & Pau-Balsa & Teca & Eucalipto & $\begin{array}{c}\text { Pastagem } \\
\text { Convencional }\end{array}$ & $\begin{array}{c}\text { Vegetação } \\
\text { Nativa }\end{array}$ \\
\cline { 2 - 7 } & & \multicolumn{5}{c}{ RSP (MPa) } \\
\hline $0,00-0,05$ & $3,98 \mathrm{bc}$ & $2,75 \mathrm{~cd}$ & $5,38 \mathrm{~b}$ & $8.93 \mathrm{a}$ & $3,75 \mathrm{bc}$ & $1,10 \mathrm{~d}$ \\
$0,05-0,10$ & $3,73 \mathrm{bc}$ & $2,86 \mathrm{c}$ & $5,81 \mathrm{~b}$ & $11,93 \mathrm{a}$ & $5,90 \mathrm{~b}$ & $1,37 \mathrm{c}$ \\
$0,10-0,15$ & $3,73 \mathrm{bc}$ & $2,86 \mathrm{c}$ & $5,81 \mathrm{~b}$ & $11,93 \mathrm{a}$ & $5,90 \mathrm{~b}$ & $1,36 \mathrm{c}$ \\
$0,15-0,20$ & $3,91 \mathrm{~b}$ & $3,31 \mathrm{~b}$ & $7,11 \mathrm{a}$ & $8,28 \mathrm{a}$ & $5,80 \mathrm{ab}$ & $3,30 \mathrm{~b}$ \\
$0,20-0,25$ & $3,53 \mathrm{~b}$ & $3,70 \mathrm{~b}$ & $6,45 \mathrm{a}$ & $6,46 \mathrm{a}$ & $5,13 \mathrm{ab}$ & $3,07 \mathrm{~b}$ \\
$0,25-0,30$ & $3,41 \mathrm{a}$ & $3,38 \mathrm{a}$ & $5,80 \mathrm{a}$ & $5,25 \mathrm{a}$ & $5,20 \mathrm{a}$ & $3,77 \mathrm{a}$ \\
$0,30-0,35$ & $4,02 \mathrm{a}$ & $2,98 \mathrm{a}$ & $4,40 \mathrm{a}$ & $4,35 \mathrm{a}$ & $4,80 \mathrm{a}$ & $4,36 \mathrm{a}$ \\
$0,35-0,40$ & $4,15 \mathrm{a}$ & $3,25 \mathrm{a}$ & $4,25 \mathrm{a}$ & $4,25 \mathrm{a}$ & $4,80 \mathrm{a}$ & $4,70 \mathrm{a}$ \\
\hline
\end{tabular}

Médias seguidas de mesma letra na linha, não diferem estatisticamente pelo teste de Tukey a $5 \%$ de probabilidade. DMS Tukey $(5 \%)=2,56$ 
A representação da resistência do solo a penetração dos diferentes usos em função das profundidades amostradas (0,00-0,40 m), destacou-se o comportamento dos usos Vegetação nativa e eucalipto, estes usos foram os únicos que apresentaram diferença significativa quanto aos valores de resistência do solo a penetração em função da profundidade (Figura 1). O comportamento do aumento gradativo da RSP com o aprofundamento do solo apresentado pelo tratamento Vegetação nativa, também foi observado por CARDOSO et al., (2011) em solo sob mata semidecídual e por CENTURION et al., (2001) em Floresta Latifoliada Tropical. Esse comportamento pode ser atribuído ao elevado acúmulo de matéria orgânica nas camadas superficiais do solo, como já abordado anteriormente. RIBON \& FILHO (2008), relataram relação direta entre a resistência à penetração e o teor de matéria orgânica da RSP em solo sob cultura perene.

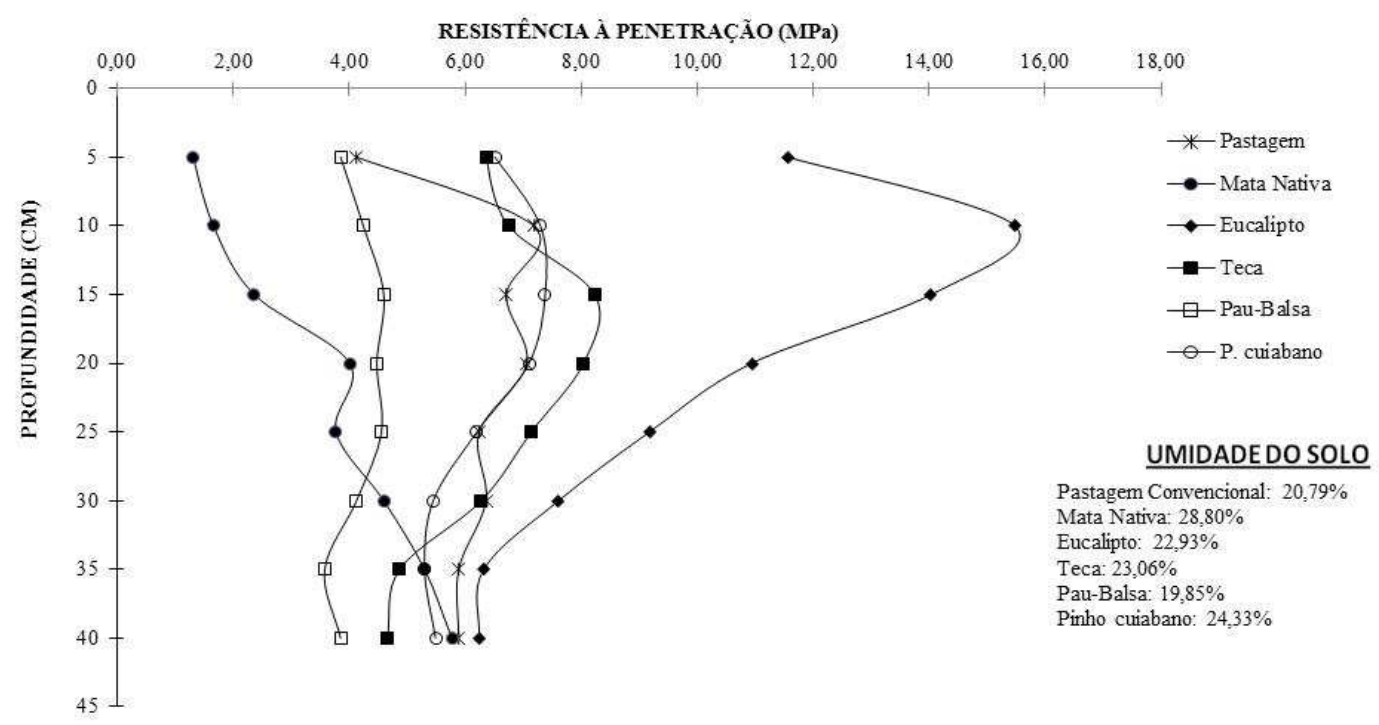

FIGURA 1. Resitência do solo à penetração nos usos avaliados, na profundidade de $0,00-0,40 \mathrm{~m}$

Diferente da vegetação nativa o tratamento eucalipto apresentou maiores valores da RSP nas camadas mais superficiais, tendo um decréscimo nas camadas mais profundas, configurando apenas uma significante compactação superficial, comportamento esse que pode estar associado à baixa umidade do solo na camada superficial, assim como descrita por LIMA et al. (2010), que avaliando RSP em reflorestamento homogêneo de eucalipto (Eucalyptus camaldulensis) observou também valores elevados de RSP, com amplitude de 3,38 à 17,54 MPa em solos com umidade gravimétrica entre 8,1 á $17,8 \%$. A compactação superficial do solo neste tratamento também pode ser associada à pressão exercida pelo pisoteio dos animais, devido ser um local usado como área descanso dos animas já que há sombreamento constante (copa das árvores) nesta área.

Com comportamento similar ao longo de todo o perfil do solo o tratamento Pinho cuiabano no local de avaliação pastagem e o tratamento Pau-balsa nos locais de avaliações pastagem e Vegetação nativa, foram os tratamentos que apresentaram valores mais próximos ao valor da RSP da vegetação nativa. Com amplitude de 3,20 à 7,60 Mpa o tratamento teca no local de avaliação floresta apresentou valores superiores da RSP ao observado por GOMES et al. (2005) em 
um reflorestamento de teca com diferentes espaçamentos, onde apresentou valores da RSP na amplitude de 1,92 à 3,11 MPa, sem a determinação da umidade do solo.

O comportamento de locais em cada uso e dos usos em cada local pode ser verificado na Tabela 5 . No local Floresta a maior resistência foi verificada para o uso eucalipto, sendo esta resistência superior aos demais usos. Como abordado anteriormente, está maior resistência se deve a presença de raízes, umidade do solo e pisoteio do gado neste local. Destaca-se novamente o uso Pau-balsa, que não diferiu da vegetação nativa.

TABELA 5. Resistência do solo à penetração (MPa) em diferentes usos e locais em Nova Canaã do Norte-MT, 2012.

\begin{tabular}{crrrrrr}
\hline \multirow{2}{*}{ Locais } & \multicolumn{7}{c}{ Usos } \\
\cline { 2 - 7 } & $\begin{array}{l}\text { Pinho } \\
\text { Cuiabano }\end{array}$ & $\begin{array}{l}\text { Pau- } \\
\text { Balsa }\end{array}$ & Teca & Eucalipto & $\begin{array}{c}\text { Pastagem } \\
\text { Convencional }\end{array}$ & $\begin{array}{l}\text { Vegetação } \\
\text { Nativa }\end{array}$ \\
\hline $\begin{array}{c}\text { Vegetação } \\
\text { Nativa }\end{array}$ & 4,38 aCD & $\begin{array}{r}3,47 \\
\text { aDE }\end{array}$ & $\begin{array}{r}6,32 \\
\text { aB }\end{array}$ & $10,41 \mathrm{aA}$ & $5,11 \mathrm{a} \mathrm{BC}$ & $2,88 \mathrm{aE}$ \\
Pastagem & $3,24 \mathrm{bB}$ & $2,80 \mathrm{bB}$ & $\begin{array}{r}4,93 \\
\mathrm{bA}\end{array}$ & $4,94 \mathrm{bA}$ & $5,11 \mathrm{aA}$ & $2,88 \mathrm{aB}$ \\
\hline
\end{tabular}

Médias seguidas de mesma letra, minúscula na coluna e maiúscula na linha, não diferem entre si ao nível de $5 \%$ de probabilidade pelo teste de Tukey

DMS Tukey 5\%: uso (local) = 1,28; Local (uso) $=0,88$

No local Pastagem, a maior resistência foi verificada no uso pastagem convencional, o qual não diferiu dos usos Eucalipto e Teca. SILVA (1993) considera que as atividades antrópicas, por menor que seja a intensidade, alteram as propriedades originais do solo, no caso da pastagem convencional, por sofrer impacto direto da chuva, pressão do pisoteio animal, pastejo intensivo e inexistência de práticas conservacionista do solo podem estar relacionadas a essa diferença significativa na RSP.

Em todos os usos com espécies florestais o local Floresta apresentou maior resistência a penetração em relação ao local Pastagem, fato esse que pode estar correlacionado a atividade agrícola realizado sob o plantio direto que antecedeu a atividade (pecuária), resultando na camada superficial, um acumulo residual de material orgânico (palhada da soja e arroz) e na camada subsuperficial o aumento da porosidade formada pelas raízes do cultivo agrícola.

Os valores da resistência do solo à penetração apresentados neste trabalho estão classificados de moderados a extremamente altos, segundo a classificação de SOIL SURVEY STAFF (1993), que considera até 2,0 MPa como uma resistência a penetração moderada e acima de $8 \mathrm{MPa}$ como extremamente alta. TORMENA \& ROLLOF (1996) consideram 2,0 MPa de RSP como um valor limitante para o crescimento e desenvolvimento de raízes ao solo. Esses valores podem estar relacionados à baixa umidade do solo e a impedimentos físicos (raizes) presentes nas áreas. LIMA et al. (2010), RIBON et al. (2003) e SILVEIRA et al. (2010) correlacionam o alto valor de RSP a umidade do solo, onde a mesma exerce efeito negativo na RSP quando o solo apresenta baixa umidade. 


\section{CONCLUSÃO}

O uso Eucalipto no local Floresta apresentaram valores elevados de RSP, devido à baixa umidade do solo na camada superficial e a pressão exercida pelo pisoteio dos animais. O uso Pau-balsa se destaca como recuperador das características físicas do solo.

\section{REFERÊNCIAS}

BALBINO, L. C.; CORDEIRO, L. A. M.; PORFÍRIO-DA-SILVA, V.; MORAES, A. de.; MARTÍNEZ, G. B.; ALVARENGA, R. C.; KICHEL, A. N.; FONTANELI, R. S.; SANTOS, H. P. dos.; FRANCHINI, J. C.; GALERANI, P. R. Evolução tecnológica e arranjos produtivos de sistemas de integração lavoura-pecuária-floresta no Brasil. Pesquisa Agropecuária Brasileira, Brasília, v. 46, n. 10, p.i-xii, 2011.

CARDOSO, E. L.; SILVA, M. L. N.; CURI, N.; FERREIRA, M. M.; FREITAS, D. A. F. $F$. Qualidade química e física do solo sob vegetação arbórea nativa e pastagens no Pantanal Sul-Mato-Grossense. Revista Brasileira de Ciência do Solo, Viçosa, v. 35, n. 2, p 613-622, 2011.

CARVALHO, R.; GOEDERT, W. J.; ARMANDO, M. S. Atributos físicos da qualidade de um solo sob sistema agroflorestal. Pesquisa Agropecuária Brasileira, Brasília, v. 39, n. 11, p. 1153-1155, 2004.

CENTURION, J. F.; CARDOSO, J. P.; NATALE, W. Efeito de formas de manejo em algumas propriedades físicas e químicas de um Latossolo Vermelho em diferentes agroecossistemas. Revista Brasileira de Engenharia Agrícola e Ambiental, Campina Grande, v. 5, n. 2. 2001.

CHIODEROLI, C. A.; MELLO, L. M. M. de.; GRIGOLLI, P. J.; FURLANI, C. E. A.; SILVA, J. O. R.; CESARIN, A. L. Atributos físicos do solo e produtividade de soja em sistemas de consórcio milho e braquiária. Revista Brasileira de Engenharia Agrícola e Ambiental, Campina Grande, v. 16, n. 1, p.37-43, 2012.

COSTA, M. A. T.; TORMENA, C. A.; LUGÃO, M. B.; FIDALSKI, J.; NASCIMENTO, W. G.; MEDEIRO, F. M. Resistência do solo à penetração e produção de raízes e de forragem em diferentes níveis de intensificação do pastejo. Revista Brasileira de Ciência do Solo, Viçosa, v. 36, n. 3, p. 993-1004, 2012.

DEBIASE, H.; FRANCHINI, J. C. Atributos físicos do solo e produtividade da soja em sistema de integração lavoura pecuária com braquiária e soja. Ciência Rural, Santa Maria, v. 42, n. 7, p. 1180-1186, 2012.

EMBRAPA - Empresa Brasileira de Pesquisa Agropecuária. Indicadores físicos e químicos de qualidade de solo de interesse agrícola. Jaguariúna, 2006. Disponível http://www.agencia.cnptia.embrapa.br/recursos/Gomes Filizola indicadoresIDu1keja1HAN.pdf. Acesso em 20 fev. 2014.

FERREIRA, D. F. Sisvar: a computer statistical analysis system. Ciência e Agrotecnologia, Lavras, v. 35, n.6, p. 1039-1042, 2011. 
FERREIRA, J.C.V. Mato Grosso e seus Municípios. Cuiabá - MT: Secretaria de Estado da Educação, 2001, 365p.

FRANCHINI, J. C.; PORFÍRIO, V. S. da. ; BALBINOT JUNIOR, A. A.; SICHIERI, F.; PADULLA, R.; DEBIASI, H.; MARTINS, S. S. Integração Lavoura-Pecuária-Floresta na Região Noroeste do Paraná. Circular Técnica, 86 - EMBRAPA Soja. Londrina PR, 2011.

GOMES, J. E.; MACEDO, R. L. G.; VENTURIN, N.; MORAIS, V. M.; SALGADO, B. G.; INÁCIO JUNIOR, C. E.; CARVALHO, E. Resistência à penetração do solo em sistemas de plantio de Tectona grandis (teca) no Cerrado do estado de Minas Gerais. Revista Científica Eletrônica de Engenharia Florestal. Garça, v. 5, p. 118, 2005.

IORI, P.; DIAS JÚNIOR, M de S.; SILVA, R. B. da. Resistência do solo à penetração e ao cisalhamento em diversos usos do solo em áreas de preservação Permanente. Bioscience Journal, v. 28, Supplement 1, p. 185-195, 2012.

LIMA, C, G. R.; CARVALHO, M. P.; NARIMATSU, K. C. P.; SILVA, M. G.; QUEIROZ, H. A. Atributos físico-químico de um latossolo do Cerrado brasileiro e sua relação com características dendrométricas do eucalipto. Revista Brasileira de Ciência do Solo, Viçosa, v. 34, n. 1, p. 163-173, 2010.

RIBON, A. A.; CENTURION, J. F.; CENTURION, M. A. P. C.; PEREIRA, G. T. Densidade e resistência a penetração de solos cultivados com seringueira sob diferentes manejos. Acta Scientiarum: Agronomy, Maringá, v. 25, n. 1, p. 13-17. 2003.

RIBON, A. A.; FILHO, J. T. Estimativa da Resistencia mecânica à penetração de um latossolo vermelho sob cultura perene no norte do estado do Paraná. Revista Brasileira de Ciência do Solo, Viçosa, v. 32, n. 5, p. 1817-1825, 2008.

SÁ, M. A. C.; JUNIOR, J. D. G. S. Considerações teóricas sobre o cálculo da resistência mecânica do solo à penetração determinada com penetrômetros dinâmicos. Documentos - Embrapa Cerrados. Planaltina - DF, 2007. Disponível em: $\quad$ http://www.infoteca.cnptia.embrapa.br/bitstream/doc/571933/1/doc200.pdf. Acessado em: 10 de jan de 2014.

SILVA, I.F. Formação, estabilidade e qualidade de agregados do solo afetados pelo uso agrícola. 1993. 137 f. Tese (Doutorado em Ciência do Solo) Universidade Federal do Rio Grande do Sul - Faculdade de Agronomia. Porto Alegre.

SILVEIRA, D. C.; MELO FILHO, J. F.; SACRAMENTO, A. A. S. do.; SILVEIRA, E. C. $P$. Relação umidade versus resistência à penetração para um argissolo amarelo distrocoeso no recôncavo da Bahia. Revista Brasileira de Ciência do solo, Viçosa, v. 34, n. 3, p. 659-667, 2010. 
SOIL SURVEY DIVISION STAFF. Examination And Description Of Soils. Soil survey manual. Soil Conservation Service. U.S Department of Agriculture Handbook 18. Cap. 3, p. 1-110, 1993.

STEFANOSKII, D.C.; SANTOS, G.G.; MARCHÃO, R. L. PETTER, F.A.; PACHECO, L.P. Uso e manejo do solo e seus impactos sobre a qualidade física. Revista brasileira de engenharia agrícola e ambiental, v.17, n.12 Campina Grande, 2013.

TORMENA, C.A.; ROLOFF, G. Dinâmica da resistência a penetração de um solo sob plantio direto. Revista Brasileira de Ciência do Solo. Campinas, v. 20, p.333-339, 1996.

YOUNG, I.M. Biophysical interactions at the root-soil interface: a review. The Journal of Agricultural Science, v. 130, n. 1, p. 1-7, 1998. 